\title{
Effects of (-)epicatechin on the pathology of APP/PS1 transgenic mice
}

\author{
Yue-Qin Zeng ${ }^{1}$, Yan-Jiang Wang ${ }^{2}$ and Xin-Fu Zhou ${ }^{1,3}$ * \\ ${ }^{1}$ Key Laboratory of Stem Cells and Regenerative Medicine, Institute of Molecular and Clinical Medicine, Kunming Medical University, Kunming, China \\ 2 Department of Neurology, Centre for Clinical Neuroscience, Daping Hospital, Third Military Medical University, Chongqing, China \\ ${ }^{3}$ School of Pharmacy and Medical Sciences, Sansom Institute, University of South Australia, Adelaide, SA, Australia
}

Edited by:

Angel Cedazo-Minguez, Karolinska Institutet, Sweden

\section{Reviewed by:}

Dione Kobayashi, Spinal Muscular

Atrophy Foundation, USA

Susan Powell, University of California

at San Diego, USA

\section{*Correspondence:}

Xin-Fu Zhou, School of Pharmacology and Medical Sciences, University of South Australia, Adelaide, SA 5000, Australia

e-mail:xin-fu.zhou@unisa.edu.au
Background: Alzheimer's disease $(A D)$ is a multifactorial disorder characterized by the progressive deterioration of neuronal networks. The clearance of $A \beta$ from the brain and anti-inflammation are potential important strategies to prevent and treat disease. In a previous study, we demonstrated the grape seed extract (GSE) could reduce brain A $\beta$ burden and microglia activation, but which polyphenol plays a major role in these events is not known. Here, we tested pharmacological effects of (-)epicatechin, one principle polyphenol compound in GSE, on transgenic AD mice.

Methods: APP/PS1 transgenic mice were fed with (-)epicatechin diet $(40 \mathrm{mg} / \mathrm{kg} / \mathrm{day})$ and curcumin diet ( $47 \mathrm{mg} / \mathrm{kg} / \mathrm{day}$ ) at 3 months of age for 9 months, the function of liver, A $\beta$ levels in the brain and serum, AD-type neuropathology, plasma levels of inflammatory cytokines were measured.

Results: Toward the end of the experiment, we found long-term feeding of (-)epicatechin diet was well tolerated without fatality, changes in food consumption, body weight, or liver function. (-)Epicatechin significantly reduced total $A \beta$ in brain and serum by 39 and $40 \%$, respectively, compared with control diet. Microgliosis and astrocytosis in the brain of Alzheimer's mice were also reduced by 38 and $35 \%$, respectively. The (-)epicatechin diet did not alter learning and memory behaviors in AD mice.

Conclusion: This study has provided evidence on the beneficial role of (-)epicatechin in ameliorating amyloid-induced AD-like pathology in AD mice, but the impact of (-)epicatechin on tau pathology is not clear, also the mechanism needs further research.

Keywords: Alzheimer's disease, A $\beta$, inflammation, (-)epicatechin, APP/PS1 transgenic mice

\section{INTRODUCTION}

Alzheimer's disease $(\mathrm{AD})$ is a neurodegenerative disorder that primarily strikes the elderly. Clinically, AD patients develop symptoms consisting of a gradual loss of memory, mental confusion, language disturbances, personality and behavioral changes, and diminished abilities for reasoning, orientation, and judgment. According to the widely accepted "amyloid hypothesis" (1), the overproduction of $A \beta$ in the brain, or failure of $A \beta$ clearance lead to brain deposition of $A \beta$ and a series of secondary pathological events, such as neurofibrillary tangle formation, neuronal dysfunction, and microglia activation, which characterize affected brain of $\operatorname{AD}(2,3)$.

$A \beta$ is regarded to play pivotal or causal roles in the development of $\mathrm{AD}$, therapeutic strategies have been mainly focused on reducing $A \beta$ production, inhibiting $A \beta$ deposition, and promoting $A \beta$ clearance (4). Accumulation of $A \beta$ in the brain and development of $\mathrm{AD}$ have been linked to dietary factors. Polyphenols are a type

Abbreviations: FA, formic acid; HPLC, high-performance liquid chromatography; IFN- $\gamma$, interferon- $\gamma$; IL-1, interleukin-1; PCR, polymerase chain reaction; SDS, sodium dodecyl sulfate; TBS, tris buffered saline; TNF- $\alpha$, tumor necrosis factor alpha. of antioxidants presenting in plant-based foods and confer significant health benefits, including protection against $\mathrm{AD}$ and other memory problems $(5,6)$.

Our previous studies have shown that polyphenols in the grape seed extract (GSE) could prevent the $A \beta$ deposition and attenuates the inflammation in the brain of a transgenic mouse mode (7). GSE, which contains various polyphenols including gallic acid, catechin, EGCG, EGC, epicatechin-3-gallate, epicatechin, and proanthocyanidins (8), but which polyphenol plays a role in $\mathrm{AD}$ pathology is not clear. As (-)epicatechin is one of a major component of polyphenols from GSE $(7,9)$, we investigate whether $(-)$ epicatechin is effective in $\mathrm{AD}$ treatment. Here, we report the beneficial effects of (-)epicatechin diet consumption on the neurodegenerative process of $\mathrm{AD}$ mice. Meanwhile, curcumin was used as a positive control, which can clean $A \beta$ deposition and ameliorate inflammation in brain of $\mathrm{AD}$ mice (7).

\section{MATERIALS AND METHODS}

\section{ANIMALS}

APP/PS1 transgenic mice were provided by Jackson Laboratories. These mice were constructed on a C57BL/6 background and bear a chimeric mouse/human (Mo/Hu) APP695 with mutations linked 
to familial AD (KM 593/594 NL) and human PS1 carrying the exon-9-deleted variant associated with familial AD (PS1dE9) in one locus under control of a brain- and neuron-specific murine Thy-1 promoter element (10). They were bred in standard animal house (at approximately 8 weeks of age, male C57BL/6 mice and female APP/PS1 mice breeding pairs, or female $\mathrm{C} 57 \mathrm{BL} / 6$ mice and male APP/PS1 mice were housed together as breeding pairs). Genotypes were determined by PCR following the provider's instruction. Mice were housed individually in standard cages with a reversed 12-h day/night cycle and provided commercial pellet diet and water ad libitum. And then, we got enough number of animals for the research.

At the age of 3 months, APP/PS1 mice were divided into three diet groups, $(-)$ epicatechin group $(N=12$, half males and half females, fed with (-)epicatechin diet), curcumin group $(N=12$, half males and half females, fed with curcumin diet) and normal diet group $(N=12$, half males and half females, fed with normal diet). Another age and sex matched wild-type littermates $(N=12$, half males and half females, fed with normal diet) were used as a control group.

All the animals were treated in strict compliance with the United States Public Health Service Policy on Human Care and Use of Laboratory Animals, the National Institutes of Health Guide for the Care and Use of Laboratory Animals, and the Guidelines for the Care and Use Laboratory Animals of the Kunming Medical University. The study had been approved by the Committee for Animal Experiments and Ethics at the Kunming Medical University.

\section{DIETARY INTERVENTION}

All experimental diets were prepared by Zoopery Centre, Kunming Medical University. The control diet was the standard commercial pelleted diet (Beijing KeaoXieli Feed Company, Beijing, China). The groups of transgenic mice treated with (-)epicatechin and curcumin ( $>95 \%$ purity by HPLC, Shanghai Tauto Biotech Co., Ltd.), respectively received doses of 40 and $47 \mathrm{mg} / \mathrm{kg} /$ day based on previous reports $(11,12)$. The animals were fed with the above diets for 9 months starting 3 months age, when no $A \beta$ plaque deposition is detectable in the brain. Food consumption and body weight data were collected every 3 months throughout the study.

\section{MORRIS WATER-MAZE TEST}

After 9 months of dietary treatment, a Morris water-maze test was used to analyze memory capability of these mice. In brief, the apparatus consisted of a circular water tank $(100 \mathrm{~cm}$ in diameter and $40 \mathrm{~cm}$ in height, filled with water in a depth of $30 \mathrm{~cm}$, at $21 \pm 1^{\circ} \mathrm{C}$ ) with a platform $(11 \mathrm{~cm}$ in diameter) set under the water $(1 \mathrm{~cm}$ below the water surface). The mice must learn to escape from water and step onto the platform. In this study, the mice were trained seven consecutive days with three trials per day. For each trial, each animal was put into the water at one of three starting positions of non-platform quadrants, respectively, and allowed at most $60 \mathrm{~s}$ free swim. The escape latency (test duration), path length (total distance traveled), and swim speed (average speed) will be recorded. (If the animal finds the platform within $60 \mathrm{~s}$, it should be stayed for an additional $30 \mathrm{~s}$ on the platform; or, it should be gently guided on the platform, and allowed to stay for $30 \mathrm{~s}$ ). On day 8, a probe trial was performed to test retention of the task. The platform was removed and each mouse was allowed $60 \mathrm{~s}$ free swim at a starting point far from the platform (starting point B). The time animal swim in the target zone, the number of crossings over the platform, and the swim track were recorded semi-automatically by the Anymaze video tracking system (Stoelting Co., USA).

\section{TISSUE SAMPLING AND PREPARATION}

At the end of the experiment, the mice were deeply anesthetized with the lethal concentration of inhaled ether, the blood was sampled from the right atrium of the heart, and then perfused with $50 \mathrm{ml}$ of normal saline, the brains were removed and bisected in the mid-sagittal plane, Left brain hemisphere was fixed in $4 \%$ paraformaldehyde ( $\mathrm{pH} 7.4$ ) for $24 \mathrm{~h}$ and incubated for $24 \mathrm{~h}$ in $30 \%$ sucrose, coronal sections of the brain were cut at $35 \mu \mathrm{m}$ thickness with a cryosectioning microtome and stored at $4^{\circ} \mathrm{C}$ in PBS containing $40 \%$ glycol for histological quantitative analysis and the right brain hemisphere was snap frozen in liquid nitrogen and stored at $-80^{\circ} \mathrm{C}$ until biochemical analysis.

\section{AD-TYPE PATHOLOGY AND QUANTITATIVE IMAGE ANALYSIS}

The left brain hemisphere was processed according to the freefloating immunohistochemistry protocol as described previously (13). Briefly, a series of five equally spaced tissue sections, spanning the entire brain were selected and stained using freefloating immunohistochemistry for total $A \beta$ (Biotin-conjugated mouse anti-A $\beta$ antibody $6 \mathrm{E} 10$, Serotec; $1: 1000$ dilution), activated microglia (rat monoclonal anti-CD45, Millipore Bioscience Research Reagents; 1:1000 dilution), and astrocyte (rabbit polyclonal anti-glial fibrilliary acidic protein, Dako, Denmark; 1:1000 dilution), respectively. Sections were incubated overnight with primary antibodies at $4^{\circ} \mathrm{C}$ and the reaction products were visualized with diaminobenzidine (No. AB500-500 Slide Kit Chemical International, Inc., Millipore).

The region of neocortex and hippocampus manually was selected for quantification of total $A \beta$ plaques, microgliosis, astrogliosis, and microhemorrhage. All images were acquired in the same session. Images were collected at $4 \times$ magnification using constant bulb temperature and exposure, yielding the area fraction of the total positive staining against the area of tissue analyzed.

Microhemorrhage (MH) staining and quantification were performed with the described method: in brief, the sections were stained with Prussian blue working solution (equal parts of freshly made $5 \%$ potassium ferrocyanide and $5 \%$ hydrochloric acid) for $30 \mathrm{~min}$ at room temperature, washed in deionized water, and counterstained with nuclear fast red. $\mathrm{MH}$ events in the form of the number of Prussian blue-positive profiles were counted in the brains of each mouse on all sections under microscope, and the average number of hemosiderin deposits was calculated per each brain hemisphere. All image analyses were processed in a blind manner.

\section{BIOCHEMICAL ASSAY}

\section{Quantification of $A \beta$ peptide levels in the mouse brain and plasma}

ELISA analysis of the brain $A \beta$ was processed as described previously (14). Briefly, frozen brain was homogenized and sonicated in TBS containing protease inhibitors. Homogenates were centrifuged at $100,000 \mathrm{~g}$ for $1 \mathrm{~h}$ at $4^{\circ} \mathrm{C}$, and the resultant supernatant 
was collected, representing the TBS-soluble fraction (A $\beta$-TBS). The resultant pellet was suspended and sonicated in water containing 2\% SDS and protease inhibitors. The SDS solubilized homogenates were centrifuged at $100,000 \times g$ for $1 \mathrm{~h}$ at $4^{\circ} \mathrm{C}$, and the resultant supernatant was collected, representing the SDSsoluble fraction $(\mathrm{A} \beta-\mathrm{SDS})$. The resultant pellet was then extracted in $70 \%$ formic acid (FA) and centrifuged, and the resultant supernatant was collected, representing the SDS-insoluble fraction $(\mathrm{A} \beta$ FA). Before ELISA assay, formic acid extracts were neutralized by 1:20 dilution into $1 \mathrm{M}$ Tris phosphate buffer, $\mathrm{pH} 11$, and then diluted in sample buffer. Concentrations of $A \beta 40$ and $A \beta 42$ in brain extract and serum were quantitatively measured by ELISA according to the manufacturer's instructions (Cat. \#EZBRAIN 40 and Cat. \#EZBRAIN 42, Millipore). Using the wet weight of brain tissue in the original homogenate, the final values of brain $A \beta$ were expressed as picograms per gram wet weight of brain.

\section{Quantification of TNF-a, IL-13, and IFN- $\gamma$ in the mouse plasma}

Tumor necrosis factor alpha (TNF- $\alpha$ ), interleukin-1 $\beta$ (IL-1 $\beta$ ), interleukin-6 (IL-6), and interferon- $\gamma$ (IFN- $\gamma$ ) in the plasma of mice were measured using ELISA kits (Cat No.BMS607/2, BMS6002, BMS606, BMS603/2 eBioscience, USA) as per manufacturer's instructions.

\section{Assessment of toxicity of (-)epicatechin}

Total bilirubin, alanine aminotransferase (ALT), and aspartate aminotransferase (AST) were analyzed by Clinical Laboratory of First Affiliated Hospital of Kunming Medical University.

\section{STATISTICAL ANALYSIS}

Unless otherwise stated, the data in the text and figures are expressed as mean \pm SEM. Statistical comparisons between groups were analyzed using $t$-test, one-way ANOVA, or two-way repeatedmeasures ANOVA for testing the significance of values. If significant, post hoc testing was done with Tukey's HSD or Dunnett's T3 methods, and appropriate $P$ values are reported based on adjustment according to Levene's test for equality of the variance. All these analyses were performed using SPSS 17.0.

\section{RESULTS}

\section{(-)EPICATECHIN IS WELL TOLERATED IN APP/PS1 TRANSGENIC MICE}

We started to feed (-)epicatechin and curcumin diet at 3 months of age. The mean daily food consumption of the mice was 0.10 $0.12 \mathrm{~g} / \mathrm{g}$ body weight, the corresponding daily (-)epicatechin consumption was $40 \mu \mathrm{g} / \mathrm{g}$ body weight and daily curcumin consumption was 77-98 $\mu \mathrm{g} / \mathrm{g}$ body weight. The equivalent consumption in a $60 \mathrm{~kg}$ human is about $0.14 \mathrm{~g} /$ day for $(-)$ epicatechin and $0.35 \mathrm{~g} /$ day for curcumin, as derived using FDA criteria for converting drug equivalent dosages across species, based on body surface area [human equivalent dose in milligrams per kilogram $=$ animal dose in milligrams per kilogram $\times$ (animal weight in kilograms per human weight in kilogram $\left.)^{0.33}\right](15)$. No difference between APP/PS1 transgenic mice and wild-type animals was found in animal viability, body weight, general activities (Figure 1A), daily food consumption (Figure 1B), and liver function, which can be reflected by the normal serum levels of bilirubin, AST, and alanine aminotransferase aspartate (ALT) (Figure 1C, the data of bilirubin was not shown because the level was below detection).

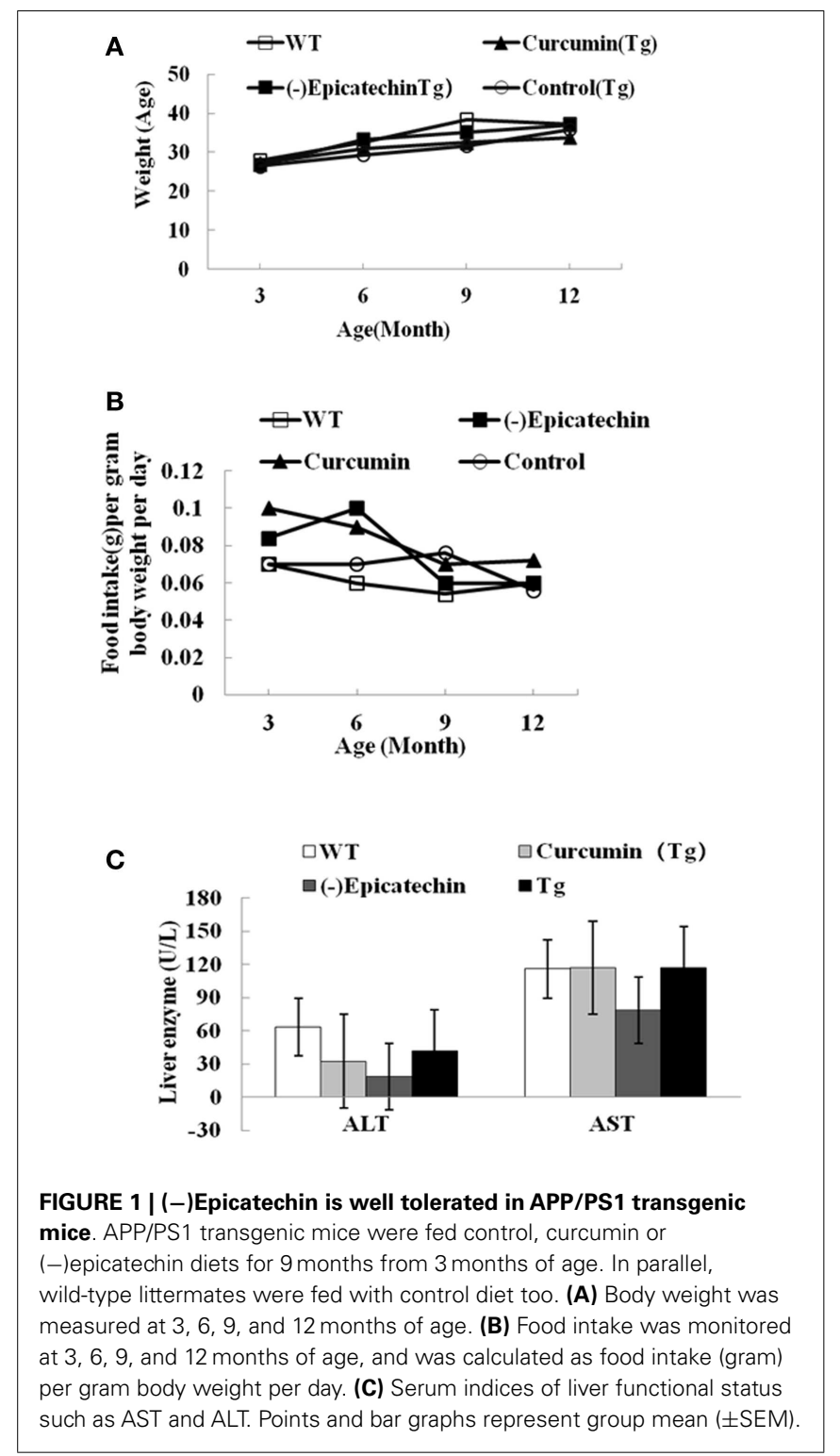

\section{EFFECTS OF (-)EPICATECHIN ON LEARNING AND MEMORY IN APP/PS1 TRANSGENIC MICE}

After 9 months treatment, all animals received behavior test. Mice were trained for 7 day with three trials per day to find the hidden platform in the Morris water maze. On day 8, mice were undergone a probe trial in which the platform was removed and the time to enter the correct quadrant where the platform had been was measured (Figure 2). But acquisition of the task did not differ between the groups (ANOVA $F=2.004, P>0.05$ ), $(-$ )epicatechin mice did not perform well on the probe trials, indicating that the (-)epicatechin did not enhance retention of spatial memory.

\section{(-)EPICATECHIN REDUCES A $\beta$ LEVELS IN THE BRAIN AND SERUM AND REDUCES AMYLOID DEPOSITION IN APP/PS1 TRANSGENIC MICE}

To assess the effect of (-)epicatechin on amyloid protein levels in the brain and the serum, the levels of both $A \beta 40$ and 42 in brain homogenates and serum were analyzed by specific sandwich 
ELISA. A $\beta$ in the SDS fraction represents soluble fraction and the diffuse $A \beta$ plaques, and $A \beta$ in the formic acid fraction represents the fibrillar $A \beta$ plaques. Total $A \beta$ level was generated from the sum of $A \beta 40$ and 42 of the different fraction.

We found significant reduction in total $A \beta$ burden in the brain of mice consuming $(-)$ epicatechin $(P<0.05)$ and curcumin diet $(P<0.01)$ when comparing to Control group (ANOVA $F=8.823$,

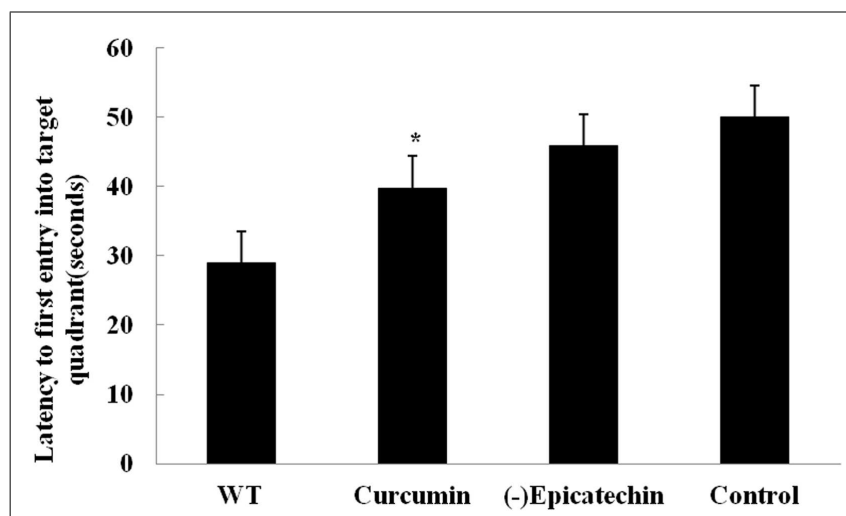

FIGURE 2 | Effect of (-)epicatechin on learning and memory in APP/PS1 transgenic mice after treated 9 months, Mice were trained for 7 day in Morriz water maze. On the 8 day performed a probe test, and the time to enter the correct quadrant where the platform had been was measured. One-way ANOVA with Student-Newman-Keuls post hoc corrections in this graph, no differences $(P>0.05)$. Bars represent mean \pm SEM. Statistical software package was SPSS17.0.
$P<0.01)$, (-)epicatechin and curcumin diet reduced total A $\beta$ burden by 39 and $51 \%$ respectively (Figure $\mathbf{3 A}$ ). Similarly, A $\beta$ levels in $2 \%$ SDS extracts of (-)epicatechin and curcumin diet groups were also reduced by 37 and $68 \%$, respectively, and the levels in the insoluble pellet in formic acid extracts were reduced by 39 and $47 \%$, respectively (Figures 3B,C, $* * * P<0.01$ ). The concentration of total $A \beta$ in the serum was also assayed by ELISA kit, the $A \beta$ level in the serum tended to be lower than that of the normal diet control group (Figure 3D), and the data did not show significant correlation with brain total A $\beta$ burden (Pearson $r=0.644$, $P=0.554)$.

Amyloid plaques on coronal sections ( $35 \mu \mathrm{M}$ thick) of the neocortical and hippocampal areas were detected with immunohistochemical staining (by CD6E10 antibody). The numbers of $\mathrm{A} \beta$ deposits were counted. Quantitative analysis showed a significant reduction of $\mathrm{A} \beta$ deposits in mice consuming ( - )epicatechin $(P<0.05)$ and curcumin diet $(P<0.01)$ compared with control diet consumption (ANOVA $F=5.310, P=0.019$ ) (Figure 4). The result is in agreement with the brain $A \beta$ levels of ELISA analysis. The total $\mathrm{A} \beta$ plaques detected by immunohistochemistry was reduced by $40 \%$ in the (-)epicatechin diet group and $55 \%$ in the curcumin diet group. These results imply beneficial effects of (-)epicatechin and curcumin, which could reduce amyloid protein aggregation.

\section{(-)EPICATECHIN PREVENTS AD-TYPE NEUROPATHOLOGY IN APP/PS1 TRANSGENIC MICE}

The microgliosis (by CD45 antibody) and astrocytosis (using GFAP antibody) in the neocortical and hippocampal regions

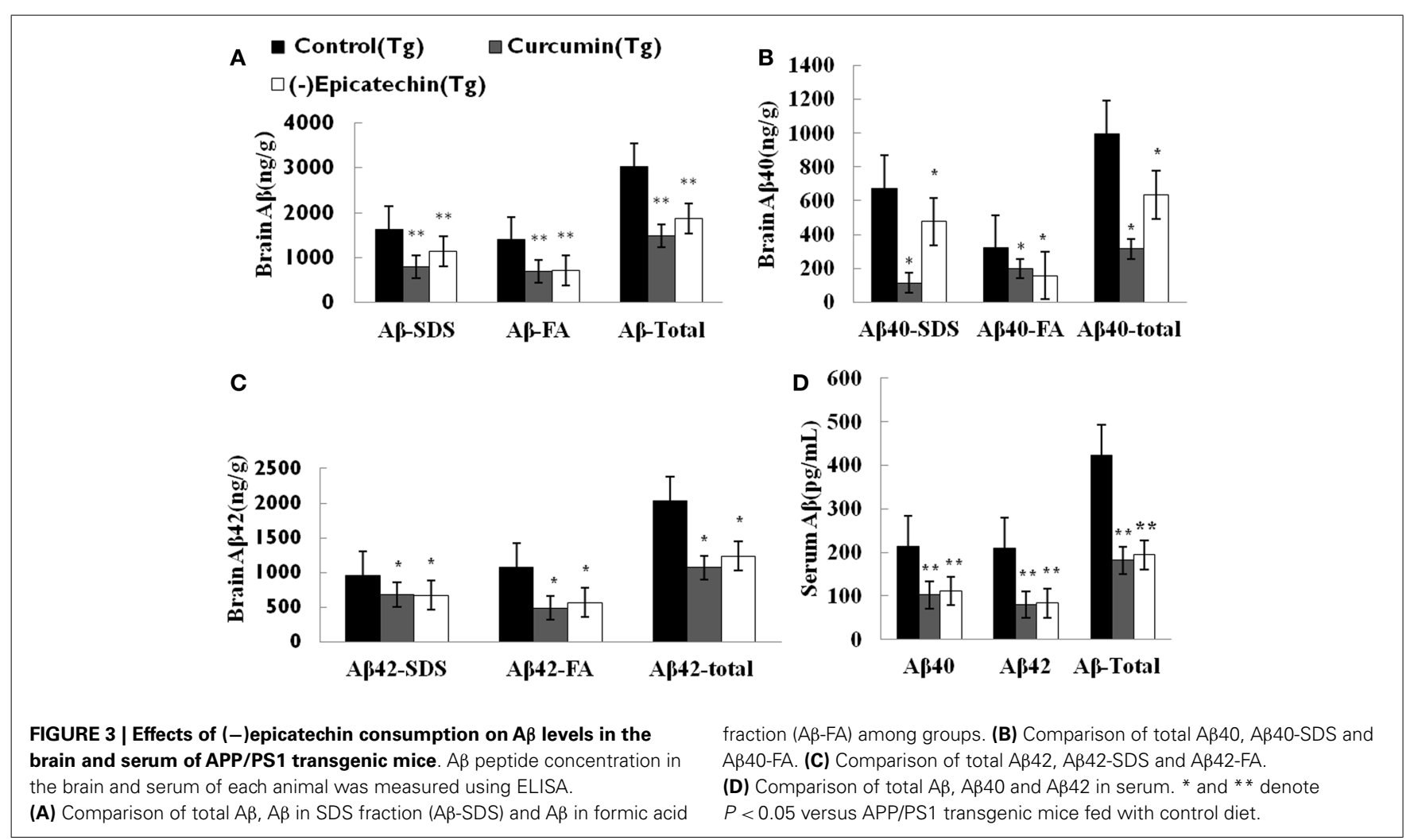




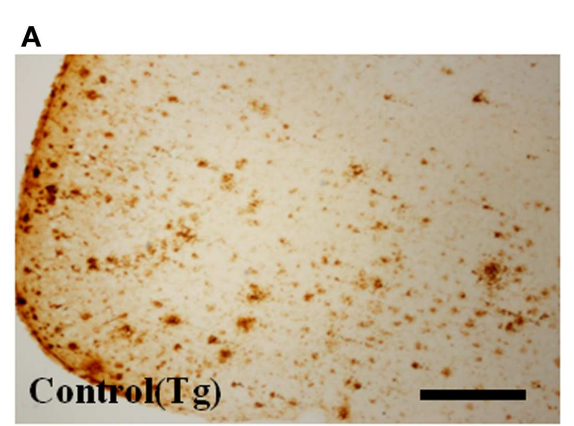

c

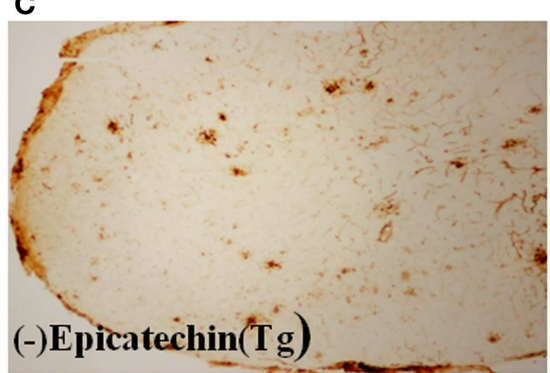

FIGURE 4 | Effects of (-)epicatechin diet on $A \beta$ deposits in the brain of the APP/PS1 transgenic mice. (A) A $\beta$ plaques of in neocortex of APP/PS1 transgenic mice fed with control diets; (B) fed with (-)epicatechin; (C) fed with curcumin; (D) comparison of $A \beta$ plaque area fraction in neocortex and
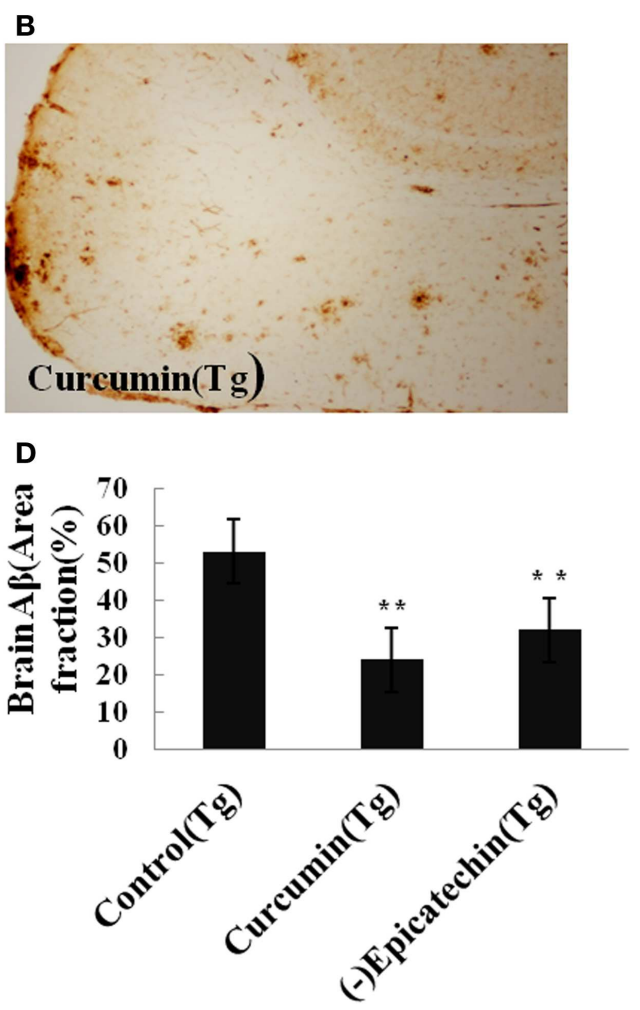

hippocampus among groups. Statistical analysis showed a significant decrease in the number of plaques in the brain treated with (-)epicatechin and curcumin diets. $P<0.05$ versus APP/PS1 transgenic mice fed with control diet. Scale bar $=0.5 \mathrm{~mm}$. were investigated by immunohistochemistry. Quantitative analysis followed by one-way ANOVA $(F=19.115, P<0.001$ and $F=6.041, P<0.05)$ revealed a remarkable differences in levels of microgliosis and astrocytosis between transgenic mice fed with (-)epicatechin diet and animals fed with control diet. The mice consuming (-)epicatechin diet showed significant lower level of microgliosis and astrocytosis by 38 and $35 \%$, but no obvious microgliosis and astrocytosis were observed in the brains of wild-type animals (Figures $\mathbf{5}$ and $\mathbf{6}$ ).

Microhemorrhage has been associated with increasing age (16, 17). In $A D, M H$ have been linked with $\beta$-amyloid $(A \beta)$ deposition in $\mathrm{AD}$ and cerebral amyloid angiopathy (CAA) (18-20). Following the previous method, we detected cerebral $\mathrm{MH}$ in brain sections stained with Iron-Prussian Blue staining. After treatment with (-)epicatechin and curcumin diets. $\mathrm{MH}$ tended to be lower than transgenic mice fed with control diet, but the difference between groups did not reach statistical significance (Dunnett T3, $P>0.05$, Figure 7).

\section{EFFECTS OF (-)EPICATECHIN TREATMENT ON INFLAMMATION CYTOKINES IN SERUM}

Inflammation is an important hall mark in $\mathrm{AD}$ development. Activated microglia mainly release a combination of both proand anti-inflammatory cytokines, including IL-1(interleukin$1)$, IFN- $\gamma$ (interferon- $\gamma$ ), TNF- $\alpha$ (tumor necrosis factor), and
IL-6 (21). Here, we measured levels of the proinflammatory cytokines in the serum using the ELISA Kits. Compared with control $(37.6 \pm 12.1 \mathrm{pg} / \mathrm{ml})$ and curcumin $(30.4 \pm 14.2 \mathrm{pg} / \mathrm{ml})$ diet, $(-)$ epicatechin $(11.6 \pm 2.8 \mathrm{pg} / \mathrm{ml})$ diet significant decreased TNF- $\alpha$ level $(P<0.05)$ in the plasma of transgenic mice (ANOVA TNF- $\alpha, F=12.261, P<0.05)$. No change was found in the cytokines of IL-1and IFN- $\gamma$ when comparing with control $(\mathrm{Tg})$ diet group (ANOVA IL- $1, F=1.428, P=0.274$; IFN- $\gamma, F=0.272$. $P=0.845$; Figure 8), and the level of IL-6 in serum was too low to be detected.

\section{DISCUSSION}

The present study suggests long-term oral (-)epicatechin as a food additive can be effective on ameliorating $\mathrm{AD}$ pathology in mice. Our results indicate that (-)epicatechin appears to be well tolerated in relation to viability and systemic toxicity by both wild-type and APP/PS1 mice. No adverse event was seen in both strains of mice. (-)Epicatechin significantly inhibited the deposits of amyloid in the brain and reduced the levels of $A \beta$ in the blood and the brain. (-)Epicatechin also attenuated neuroinflammation in APP/PS1 mice, including reducing levels of microgliasis and astrogliosis and lowering the concentration of TNF- $\alpha$ in the plasma of transgenic mice. But (-)epicatechin did not improve learning and memory in APP/PS1 mice after 9 months treatment. This result is different from a previous report showing that the 


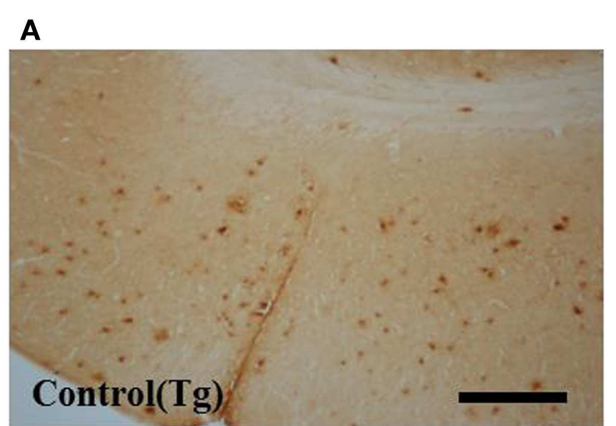

C
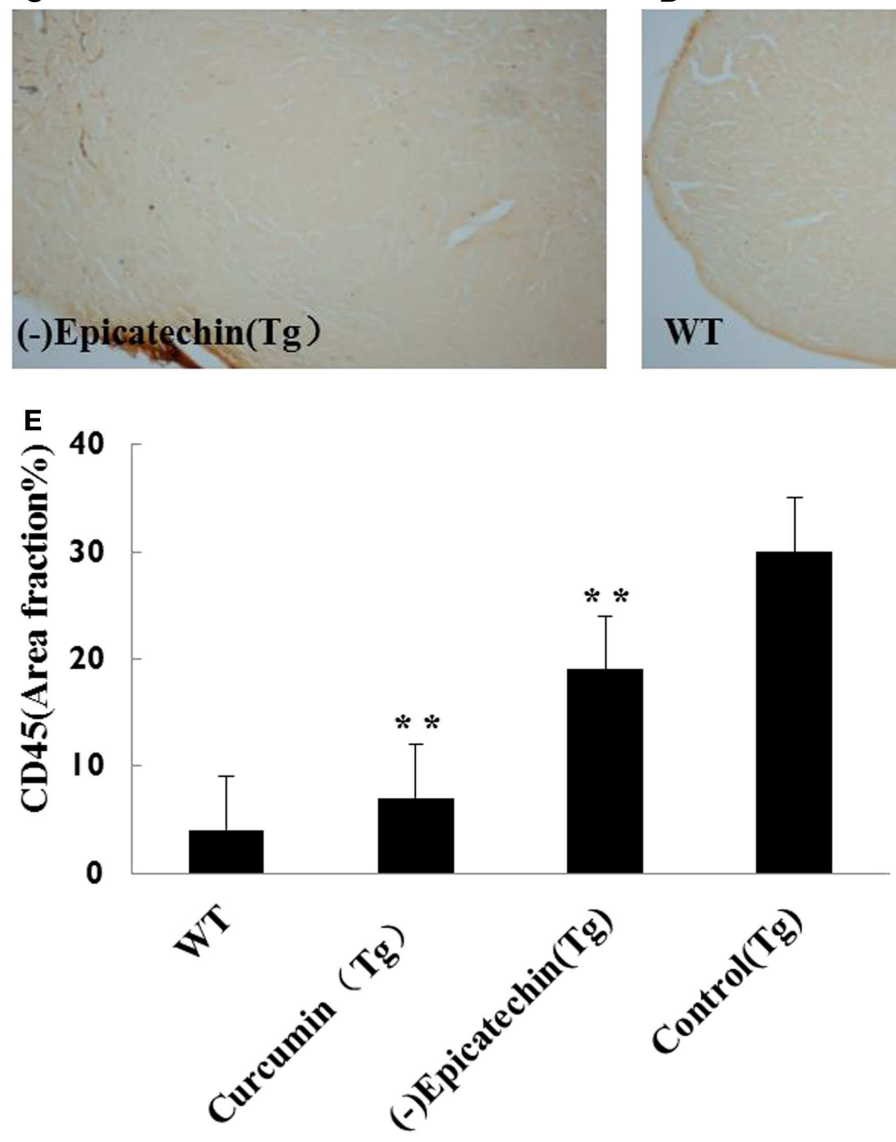

\section{B}

\section{Curcumin(Tg)}

D

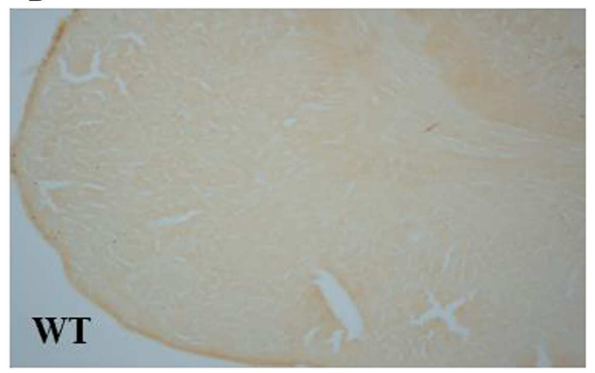

FIGURE 5 | Effects of (-)epicatechin diet group on microgliosis in the brain. The area of neocortex and hippocampus was selected for quantification of activated microglia immunostaining. (A) Microgliosis in hippocampus and neocortex of APP/PS1 transgenic mice fed with control diet, (B) transgenic mouse fed with curcumin, (C) transgenic mouse fed with (-)epicatechin, (D) wild-type mouse fed with control diet, (E) Comparison of CD45 area fraction in neocortex and hippocampus among groups. Statistical analysis showed a significant decrease in the number of microgliosis in the brain treated with (-)epicatechin and curcumin diets. $P<0.05$ versus APP/PS1 transgenic mice fed with control diet. Scale bar $=0.5 \mathrm{~mm}$. Original magnification, $4 \times$. consumption of $(-)$ epicatechin increases memory function of normal mice (22) and this difference can be ascribed to different strains of mice, dosage, and length of treatment.

Soluble $A \beta$ oligomers are major contributors to the toxicity associated with the peptide. The amyloid peptides $A \beta 40$ and 42 are thought to contribute differentially to the disease process (23). It is found that $A \beta 42$ is much more prone to aggregate and more toxic to neurons than $A \beta 40(24,25)$. We examined $A \beta$ levels in the $2 \%$ SDS and formic acid by ELISA. While A $\beta 42$ and 40 levels are decreased in animals fed with $(-)$ epicatechin relative to untreated $\mathrm{AD}$ transgenic animals (Dunnett's T3 Assay, $P<0.05$ ), the ratio of insoluble $A \beta 42 / 40$ was significantly decreased in (-)epicatechin diet fed mice (1.95) relative to fed standard diet mice (2.05).

The decreased ratio (5\%) of insoluble $A \beta 42 / 40$ in (-)epicatechin consumption mice may be attributable to the 

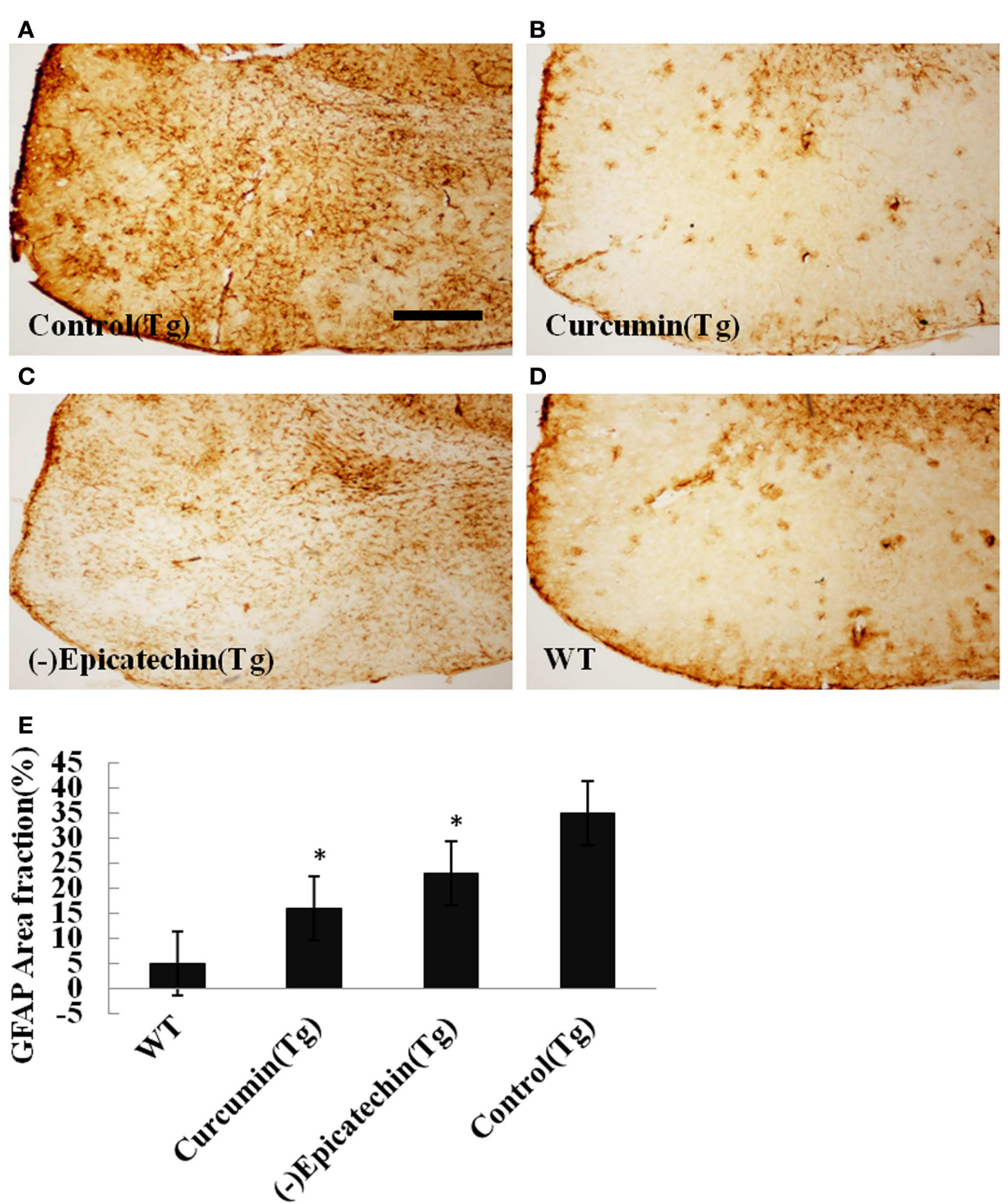

FIGURE 6 | Effects of (-)epicatechin diet group on astrogliosis in the brain. The area of neocortex and hippocampus was selected for quantification of astrogliosis immunostaining. (A) Astrogliosis in hippocampus and neocortex of APP/PS1 transgenic mice fed with control, (B) transgenic mouse fed with curcumin, (C) transgenic mouse fed with (-)epicatechin,
(D) wild-type mouse fed with control diets, (E) comparison of GFAP area fraction in neocortex and hippocampus among groups. Statistical analysis showed a significantly decrease in the astrogliosis in the brain treated with (-)epicatechin and curcumin diets. $P<0.05$ versus APP/PS1 transgenic mice fed with control diet. Scale bar $=0.5 \mathrm{~mm}$. Original magnification, $4 \times$. modulation of $\beta$-secretase inhibition. $\beta$-secretase is one of important enzymes in the process of APP to A $\beta 42$ (26). However, significant change in the $\beta$-secretase activity as measured BACE activity assays, suggests that $\beta$-secretase may not play a role in $\mathrm{A} \beta$ reduction caused by $(-)$ epicatechin diet. However, we cannot rule out the possibility that the $\gamma$-secretase is involved in $\mathrm{A} \beta$ metabolism in (-)epicathechin treated mice, $\gamma$-secretase is a large multimeric membrane-bound protein composed of presenilins (PS1), nicastrin, and Aph-1. Mutations in three different genes, APP and presenilin-1 and -2 (PS1 and PS2), are known to cause early onset familial $\mathrm{AD}(27,28)$. For this reason, $\boldsymbol{\gamma}$-secretase has been considered as a plausible molecular target as a means to interfere with the production of $A \beta$. Inhibiting $\gamma$-site cleavages of $\gamma$-secretase is a more attractive approach, which using an APP/A $\beta$-binding small molecular compound can achieve allosteric modulation of $\gamma$-secretase activity and attenuate the $A \beta 42 / 40$ ratio (29), additional work is required to understand if $(-$ )epicatechin directly target the $\gamma$-secretase.

$(-)$ Epicatechin is a flavonoid, possesses free radical scavenging activity and superoxide dismutase activity (30-32). $(-)$ Epicatechin is able to traverse the blood-brain barrier after oral ingestion $(33,34)$, so it is possible that $A \beta$ neurotoxicity be blocked by an antioxidant mechanism, and by inhibition of Amyloid-beta oligomers and/or fibril formation (35). 
Inflammation is considered a major pathological aspect of $\mathrm{AD}$. As a part of the inflammatory response, activated astrocytes and microglia are characteristically found in abundance in the plaques. Besides, AD brains show increased expression of several proinflammatory cytokines such as IL-6, IL-1 $\beta$, and tumor necrosis factor- $\alpha$ (TNF- $\alpha)$, which are hardly detectable in normal brains (36-39). Increased levels of these cytokines have been described not only in the brains but also in blood and cerebrospinal fluid from $\mathrm{AD}$ patients (40).

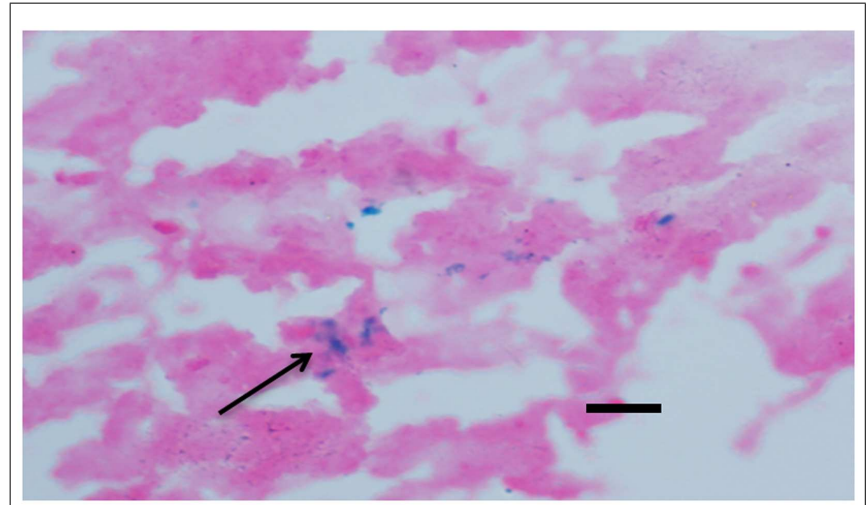

FIGURE 7 | Effects of (-)epicatechin and curcumin consumption on microhemorrhage profiles. Microhemorrhage events in the form of the number of Prussian blue-positive profiles were counted, and the average number and standard error of hemosiderin deposits was calculated per each brain hemisphere. Comparison of microhemorrhage profiles per each brain hemisphere among groups. ${ }^{*},{ }^{*}$ denote $P>0.05$ versus wild-type littermate fed with Control diet.
In this study, our results showed the chronic (-)epicatechin consumption effectively alleviated microgliosis and astrogliosis, and reduced level of TNF- $\alpha$ among transgenic mice. This is consistent with the fact that inhibition of TNF- $\alpha$ by various means reduces $\mathrm{AD}$-like pathology in transgenic $\mathrm{AD}$ mice $(41,42)$. In addition, the levels of IL- $1 \beta$ and IFN- $\gamma$ in serum did not change and the level of IL- 6 was too low to be detected. The data are consistent with our previous studies (13), indicating (-)epicatechin can suppress inflammation in the mouse model of AD.

Although $\mathrm{A} \beta$ is the initial factor of the $\mathrm{AD}$ pathogenesis, recent efforts to reduce Abeta production or clear Abeta deposition in the brain did not success in clinical trials, such as beta- or gammasecretase inhibitor and immunotherapies (43). The lessons learnt from these failures suggest that an effective therapy should simultaneously target different aspects of $\mathrm{AD}$ pathogenesis, as $\mathrm{AD}$ is a multifactorial disease. Neuroinflammation and oxidative stress are key components of AD pathogenesis. Although they are secondary to Abeta deposition, they play critical roles in promoting AD development and progress, via increasing Abeta production, enhancing Abeta deposition, and cause other pathological events such as tau hyperphosphorylation, neuronal degeneration, and death. In this regard, polyphenols possess their own advantages. So far, some polyphenols have been suggested to be able to reduce Abeta production, inhibit Abeta aggregation, attenuate neuroinflammation and oxidative stress, ameliorate tau hyperphosphorylation (4446). Thus, polyphenols possibly represent a group of natural drug candidate for $\mathrm{AD}$.

In summary, our research confirms the efficacy of (-)epicatechin in APP/PS1 mice AD, but the impact of (-)epicatechin on tau pathology is not clear, also the mechanism needs further research.

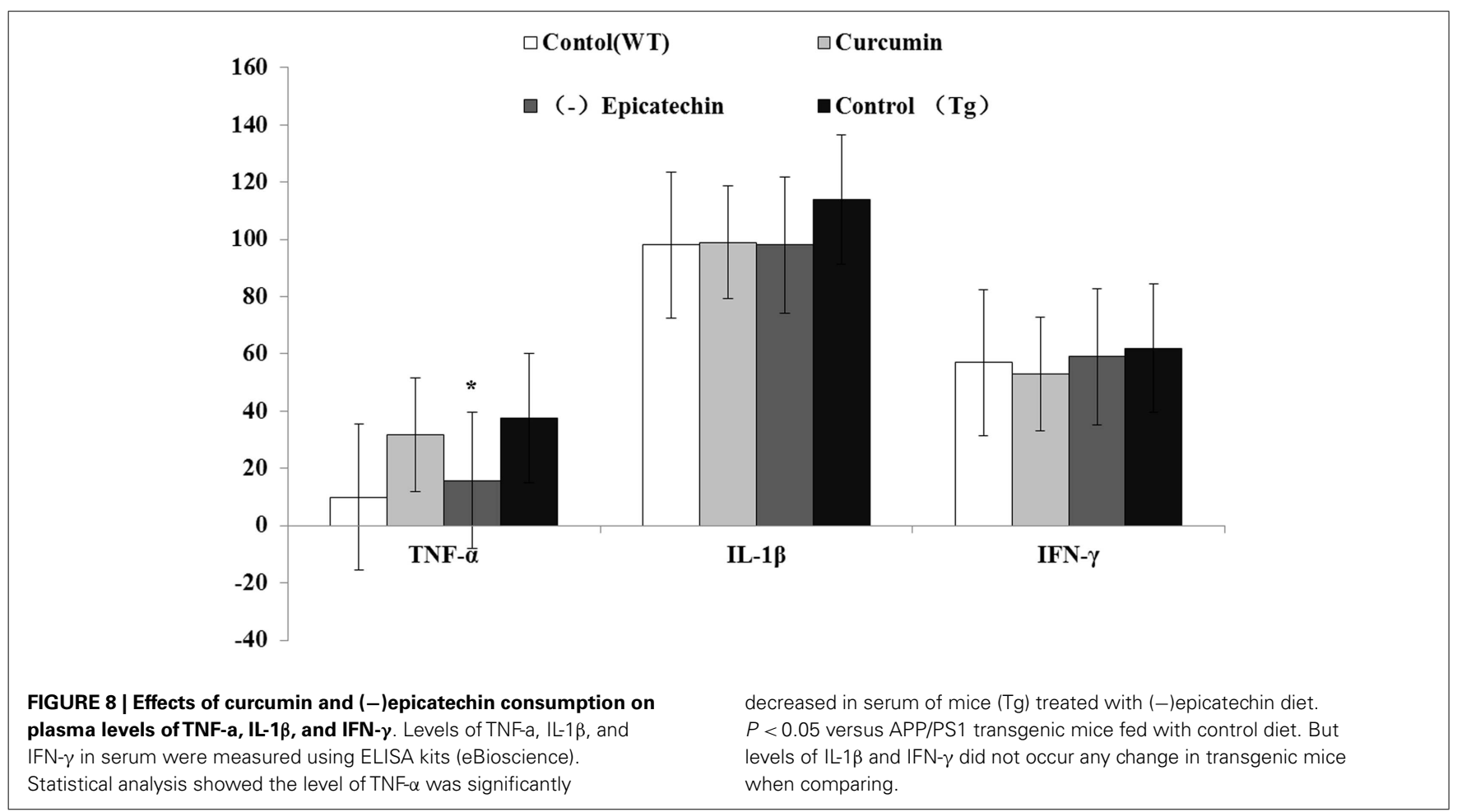




\section{ACKNOWLEDGMENTS}

This work was supported by grants from MOST (2011CB944200), and NHMRC APP1021409. Xin-Fu Zhou is a visiting professor of Kunming Medical University.

\section{REFERENCES}

1. Hardy J, Selkoe DJ. The amyloid hypothesis of Alzheimer's disease: progress and problems on the road to therapeutics. Science (2002) 297(5580):353-6. doi:10.1126/science.1072994

2. Braak H, Alafuzoff I, Arzberger T, Kretzschmar H, Del Tredici K. Staging of Alzheimer disease-associated neurofibrillary pathology using paraffin sections and immunocytochemistry. Acta Neuropathol (2006) 112(4):389-404. doi:10.1007/s00401-006-0127-z

3. Bellucci A, Bugiani O, Ghetti B, Spillantini MG. Presence of reactive microglia and neuroinflammatory mediators in a case of frontotemporal dementia with P301s mutation. Neurodegener Dis (2011) 8(4):221-9. doi:10.1159/ 000322228

4. Wang YJ, Zhou HD, Zhou XF. Clearance of amyloid-beta in Alzheimer's disease: progress, problems and perspectives. Drug Discov Today (2006) 11(1920):931-8. doi:10.1016/j.drudis.2006.08.004

5. Qin XY, Cheng Y, Yu LC. Potential protection of green tea polyphenols against intracellular amyloid beta-induced toxicity on primary cultured prefrontal cortical neurons of rats. Neurosci Lett (2012) 513(2):170-3. doi:10.1016/j.neulet. 2012.02.029

6. Bhullar KS, Rupasinghe HP. Polyphenols: multipotent therapeutic agents in neurodegenerative diseases. Oxid Med Cell Longev (2013) 2013:891748. doi:10. $1155 / 2013 / 891748$

7. Wang YJ, Thomas P, Zhong JH, Bi FF, Kosaraju S, Pollard A, et al. Consumption of grape seed extract prevents amyloid-beta deposition and attenuates inflammation in brain of an Alzheimer's disease mouse. Neurotox Res (2009) 15(1):3-14. doi:10.1007/s12640-009-9000-x

8. Kim EY, Ham SK, Shigenaga MK, Han O. Bioactive dietary polyphenolic compounds reduce nonheme iron transport across human intestinal cell monolayers. J Nutr (2008) 138(9):1647-51.

9. Thomas P, Wang YJ, Zhong JH, Kosaraju S, O’Callaghan NJ, Zhou XF, et al. Grape seed polyphenols and curcumin reduce genomic instability events in a transgenic mouse model for Alzheimer's disease. Mutat Res (2009) 661(1-2):25-34. doi:10.1016/j.mrfmmm.2008.10.016

10. Jankowsky JL, Slunt HH, Ratovitski T, Jenkins NA, Copeland NG, Borchelt DR. Co-expression of multiple transgenes in mouse CNS: a comparison of strategies. Biomol Eng (2001) 17:157-65. doi:10.1016/S1389-0344(01)00067-3

11. Papiez MA, Baran J, Bukowska-Strakova K, Wiczkowski W. Antileukemic action of (-)-epicatechin in the spleen of rats with acute myeloid leukemia. Food Chem Toxicol (2010) 48(12):3391-7. doi:10.1016/j.fct.2010.09.010

12. Yang F, Lim GP, Begum AN, Ubeda OJ, Simmons MR, Ambegaokar SS, et al. Curcumin inhibits formation of amyloid beta oligomers and fibrils, binds plaques, and reduces amyloid in vivo. J Biol Chem (2005) 280(7):5892-901. doi:10.1074/jbc.M404751200

13. Wang YJ, Pollard A, Zhong JH, Dong XY, Wu XB, Zhou HD, et al. Intramuscular delivery of a single chain antibody gene reduces brain Abeta burden in a mouse model of Alzheimer's disease. Neurobiol Aging (2009) 30(3):364-76. doi:10.1016/j.neurobiolaging.2007.06.013

14. Wang YJ, Wang X, Lu JJ, Li QX, Gao CY, Liu XH, et al. p75NTR regulates Abeta deposition by increasing Abeta production but inhibiting Abeta aggregation with its extracellular domain. J Neurosci (2011) 31(6):2292-304. doi:10.1523/JNEUROSCI.2733-10.2011

15. U.S. Department of Health and Human Services, Food and Drug Administration, Center for Drug Evaluation and Research (CDER). Pharmacology and Toxicology. Guidance for Industry: Estimating the Maximum Safe Dose in Initial Clinical Trials for Therapeutics in Adult Healthy Volunteers (2005). p. 7.

16. Fisher M, Vasilevko V, Passos GF, Ventura C, Quiring D, Cribbs DH. Therapeutic modulation of cerebral microhemorrhage in a mouse model of cerebral amyloid angiopathy. Stroke (2011) 42(11):3300-3. doi:10.1161/STROKEAHA.111. 626655
17. Yates PA, Sirisriro R, Villemagne VL, Farquharson S, Masters CL, Rowe CC, et al. Cerebral microhemorrhage and brain $\beta$-amyloid in aging and Alzheimer disease. Neurology (2011) 77(1):48-54. doi:10.1212/WNL.0b013e318221ad36

18. Klunk WE, Engler H, Nordberg A, Wang Y, Blomqvist G, Holt DP, et al. Imaging brain amyloid in Alzheimer's disease with Pittsburgh compound B. Ann Neurol (2004) 5(3):306-19. doi:10.1002/ana.20009

19. Johnson KA, Gregas M, Becker JA, Kinnecom C, Salat DH, Moran EK, et al. Imaging of amyloid burden and distribution in cerebral amyloid angiopathy. Ann Neurol (2007) 62(3):229-34. doi:10.1002/ana.21164

20. Ly JV, Donnan GA, Villemagne VL, Zavala JA, Ma H, O'Keefe G, et al. 11C-PIB binding is increased in patients with cerebral amyloid angiopathy-related hemorrhage. Neurology (2010) 74(9):487-93. doi:10.1212/WNL.0b013e3181cef7e3

21. Johnston H, Boutin H, Allan SM. Assessing the contribution of inflammation in models of Alzheimer's disease. Biochem Soc Trans (2011) 39(4):886-90. doi:10.1042/BST0390886

22. van Praag H, Lucero MJ, Yeo GW, Stecker K, Heivand N, Zhao C, et al. Plantderived flavanol (-)epicatechin enhances angiogenesis and retention of spatial memory in mice. J Neurosci (2007) 27(22):5869-78. doi:10.1523/JNEUROSCI. 0914-07.2007

23. Krafft GA, Klein WL. Addls and the signaling web that leads to Alzheimer's disease. Neuropharmacology (2010) 59(4-5):230-42. doi:10.1016/j.neuropharm. 2010.07.012

24. Russo I, Barlati S, Bosetti F. Effects of neuroinflammation on the regenerative capacity of brain stem cells. J Neurochem (2011) 116(6):947-56. doi:10.1111/j. 1471-4159.2010.07168.x

25. Yan Y, Wang C. Abeta42 is more rigid than Abeta40 at the C terminus: implications for Abeta aggregation and toxicity. J Mol Biol (2006) 364(5):853-62. doi:10.1016/j.jmb.2006.09.046

26. Wang H, Megill A, He K, Kirkwood A, Lee HK. Consequences of inhibiting amyloid precursor protein processing enzymes on synaptic function and plasticity. Neural Plast (2012) 2012:272374. doi:10.1155/2012/272374

27. Kounnas MZ, Danks AM, Cheng S, Tyree C, Ackerman E, Zhang X, et al. Modulation of gamma-secretase reduces beta-amyloid deposition in a transgenic mouse model of Alzheimer's disease. Neuron (2010) 67(5):769-80. doi:10.1016/j.neuron.2010.08.018

28. Wagner SL, Tanzi RE, Mobley WC, Galasko D. Potential use of gammasecretase modulators in the treatment of Alzheimer disease. Arch Neurol (2012) 69(10):1255-8. doi:10.1001/archneurol.2012.540

29. Weggen S, Eriksen JL, Das P, Sagi SA, Wang R, Pietrzik CU, et al. A subset of NSAIDs lower amyloidogenic A $\beta 42$ independently of cyclooxygenase activity. Lett Nat (2001) 414(8):6. doi:10.1038/35102234

30. Kostyuk VA, Potapovich AI, Strigunova EN, Kostyuk TV, Afanas'ev IB. Experimental evidence that flavonoid metal complexes may act as mimics of superoxide dismutase. Arch Biochem Biophys (2004) 428(2):204-8. doi:10.1016/j.abb.2004. 06.008

31. Ishige K, Schubert D, Sagara Y. Flavonoids protect neuronal cells from oxidative stress by three distinct mechanisms. Free Radic Biol Med (2001) 30(4):433-46. doi:10.1016/S0891-5849(00)00498-6

32. Cuevas E, Limon D, Perez-Severiano F, Diaz A, Ortega L, Zenteno E, et al. Antioxidant effects of epicatechin on the hippocampal toxicity caused by amyloid-beta 25-35 in rats. Eur J Pharmacol (2009) 616(1-3):122-7. doi:10.1016/j.ejphar. 2009.06.013

33. Fruson L, Dalesman S, Lukowiak K. A flavonol present in cocoa [(-)epicatechin] enhances snail memory. J Exp Biol (2012) 215(Pt 20):3566-76. doi:10.1242/jeb. 070300

34. Schroeter H, Bahia P, Spencer JP, Sheppard O, Rattray M, Cadenas E, et al. (-)Epicatechin stimulates ERK-dependent cyclic AMP response element activity and up-regulates GluR2 in cortical neurons. J Neurochem (2007) 101(6):1596-606. doi:10.1111/j.1471-4159.2006.04434.x

35. Porat Y, Abramowitz A, Gazit E. Inhibition of amyloid fibril formation by polyphenols: structural similarity and aromatic interactions as a common inhibition mechanism. Chem Biol Drug Des (2006) 67(1):27-37. doi:10.1111/j.17470285.2005.00318.x

36. Griffin WS, Mrak RE. Interleukin-1 in the genesis and progression of and risk for development of neuronal degeneration in Alzheimer's disease. J Leukoc Biol (2002) 72(2):233-8. 
37. Griffin WS, Barger SW. Neuroinflammatory cytokines - the common thread in Alzheimer pathogenesis. US Neurol (2010) 6(2):19-27.

38. Mrak RE, Griffin WS. Glia and their cytokines in progression of neurodegeneration. Neurobiol Aging (2005) 26(3):349-54. doi:10.1016/j.neurobiolaging.2004. 05.010

39. Vasto S, Candore G, Listi F, Balistreri CR, Colonna-Romano G, Malavolta M, et al. Inflammation, genes and zinc in Alzheimer's disease. Brain Res Rev (2008) 58(1):96-105. doi:10.1016/j.brainresrev.2007.12.001

40. Fuster-Matanzo A, Llorens-Martin M, Hernandez F, Avila J. Role of neuroinflammation in adult neurogenesis and Alzheimer disease: therapeutic approaches. Mediators Inflamm (2013) 2013:260925. doi:10.1155/2013/260925

41. He P, Zhong Z, Lindholm K, Berning L, Lee W, Lemere C, et al. Deletion of tumor necrosis factor death receptor inhibits amyloid beta generation and prevents learning and memory deficits in Alzheimer's mice. J Cell Biol (2007) 178(5):829-41. doi:10.1083/jcb.200705042

42. Shi JQ, Shen W, Chen J, Wang BR, Zhong LL, Zhu YW, et al. Anti-TNF-alpha reduces amyloid plaques and tau phosphorylation and induces CD11c-positive dendritic-like cell in the APP/PS1 transgenic mouse brains. Brain Res (2011) 1368:239-47. doi:10.1016/j.brainres.2010.10.053

43. Liu YH, Zeng F, Wang YR, Zhou HD, Giunta B, Tan J, et al. Immunity and Alzheimer's disease: immunological perspectives on the development of novel therapies. Drug Discov Today (2013) 18(23-24):1212-20. doi:10.1016/j.drudis. 2013.07.020

44. Griffin WS. Inflammation and neurodegenerative diseases. Am J Clin Nutr (2006) 83(2):470S-4S.
45. Wang J, Ho L, Zhao W, Ono K, Rosensweig C, Chen L, et al. Grape-derived polyphenolics prevent Abeta oligomerization and attenuate cognitive deterioration in a mouse model of Alzheimer's disease. J Neurosci (2008) 28(25):6388-92.

46. Rezai-Zadeh K. Green tea epigallocatechin-3-gallate (EGCG) modulates amyloid precursor protein cleavage and reduces cerebral amyloidosis in Alzheimer transgenic mice. J Neurosci (2005) 25(38):8807-14. doi:10.1523/JNEUROSCI. 1521-05.2005

Conflict of Interest Statement: The authors declare that the research was conducted in the absence of any commercial or financial relationships that could be construed as a potential conflict of interest.

Received: 08 February 2014; accepted: 24 April 2014; published online: 09 May 2014. Citation: Zeng Y-Q, Wang Y-J and Zhou X-F (2014) Effects of (-)epicatechin on the pathology of APP/PS1 transgenic mice. Front. Neurol. 5:69. doi: 10.3389/fneur.2014.00069

This article was submitted to Neuropharmacology, a section of the journal Frontiers in Neurology.

Copyright (C) 2014 Zeng, Wang and Zhou. This is an open-access article distributed under the terms of the Creative Commons Attribution License (CC BY). The use, distribution or reproduction in other forums is permitted, provided the original author(s) or licensor are credited and that the original publication in this journal is cited, in accordance with accepted academic practice. No use, distribution or reproduction is permitted which does not comply with these terms. 